\title{
Uptake kinetics of 3-buten-1-ol, 4-penten-1-ol and 3-methyl-3-buten-1-ol into sulfuric acid solutions
}

\author{
XU ZhiFang ${ }^{1,2}$, LIU Ze $^{2}$, GE MaoFa $^{2 *} \&$ WANG WeiGang ${ }^{2}$ \\ ${ }^{1}$ Key Laboratory of Engineering Geomechanics, Institute of Geology and Geophysics, Chinese Academy of Sciences, Beijing 100029, China; \\ ${ }^{2}$ State Key Laboratory for Structural Chemistry of Unstable and Stable Species, Beijing National Laboratory for Molecular Sciences Institute of \\ Chemistry, Chinese Academy of Sciences, Beijing 100190, China
}

Received June 17, 2010; accepted September 7, 2010

\begin{abstract}
Unsaturated alcohols are important components in complex mixtures of oxygenated volatile organic compounds, and play a significant role in atmospheric chemistry. The uptake kinetics of 3-buten-1-ol (BO31), 4-penten-1-ol (PO41) and 3-methyl3-buten-1-ol (MBO331) into $20 \mathrm{wt} \%-80 \mathrm{wt} \% \mathrm{H}_{2} \mathrm{SO}_{4}$ solutions were studied, using a rotated wetted-wall reactor coupled to a differentially pumped single-photon ionization time of flight mass spectrometer (SPI-TOFMS). With increasing acidity, the uptake processes changed from reversible to irreversible (reactive). Reactive uptake was observed in $60 \mathrm{wt} \%-80 \mathrm{wt} \%, 50 \mathrm{wt} \%-80 \mathrm{wt} \%$ and $30 \mathrm{wt} \%-80 \mathrm{wt} \% \mathrm{H}_{2} \mathrm{SO}_{4}$ solutions for $\mathrm{BO} 31, \mathrm{PO} 41$ and $\mathrm{MBO} 331$, respectively. Reactive uptake coefficients were acquired and are reported here for the first time. Reactivity order followed the trend: BO31<PO41<MBO331. An electrophilic addition mechanism of $\mathrm{H}_{2} \mathrm{SO}_{4}$ to the $\mathrm{C}=\mathrm{C}$ double bond was used to explain this trend. Atmospheric implications were discussed, based on the reactive uptake coefficients. This heterogeneous reaction with sulfuric acid aerosols may be a potential degradation pathway of unsaturated alcohols, and should not be neglected.
\end{abstract}

heterogeneous reaction, unsaturated alcohols, reactive uptake coefficients, sulfuric acid, OVOCs

Citation: $\quad \mathrm{Xu} \mathrm{Z} \mathrm{F,} \mathrm{Liu} \mathrm{Z,} \mathrm{Ge} \mathrm{M} \mathrm{F,} \mathrm{et} \mathrm{al.} \mathrm{Uptake} \mathrm{kinetics} \mathrm{of} \mathrm{3-buten-1-ol,} \mathrm{4-penten-1-ol} \mathrm{and} \mathrm{3-methyl-3-buten-1-ol} \mathrm{into} \mathrm{sulfuric} \mathrm{acid} \mathrm{solutions.} \mathrm{Chinese} \mathrm{Sci} \mathrm{Bull,}$ 2011, 56: 1352-1356, doi: 10.1007/s11434-011-4461-8

The scientific community has recently given increasing attention to oxygenated volatile organic compounds (OVOCs), because such species are thought to be important in atmospheric chemistry. Studies have also shown that interactions between OVOCs and acidic particles may have relevance in the formation of secondary organic aerosols [1-4]. Examples of OVOCs are some unsaturated alcohols, which are emitted as primary pollutants from various biogenic and anthropogenic sources. Goldan et al. [5] found that the concentration of 2-methyl-3-buten-2-ol (MBO232) could reach levels of several $\mathrm{ppb}$ at a remote Colorado mountain site, exceeding levels of isoprene by a factor of between five and eight. The emission of 3-methyl-2-buten1-ol (MBO321) and 3-methyl-3-buten-1-ol (MBO331) has

*Corresponding author (email: gemaofa@iccas.ac.cn) been observed from different vegetation types [6]. Pentenols emitted during leaf drying, senescence, and following freeze-thaw damage were detected by Fall et al. [7]. Other alcohols including 2-buten-1-ol (BO21), 2-methyl-2-propen1-ol (MPO221) and 3-buten-1-ol (BO31) are also re- leased into the atmosphere during polymer synthesis processes in plastic industries.

These unsaturated alcohols can be removed by reaction with hydroxyl $(\mathrm{OH})$ radicals, ozone $\left(\mathrm{O}_{3}\right)$, nitrate $\left(\mathrm{NO}_{3}\right)$ radicals, and sometimes also chlorine $(\mathrm{Cl})$, once they enter the atmosphere [8-11]. Compared to researches of these homogeneous reactions, the amount of studies on heterogeneous processes was less, particularly regarding kinetic factors that are necessary for assessing their atmospheric impact. Because of lower volatility than corresponding alkenes, unsaturated alcohols can more readily partition into 
atmospheric aerosols. Nozière et al. [12] performed uptake experiments of $\mathrm{MBO} 232$ into sulfuric acid $\left(\mathrm{H}_{2} \mathrm{SO}_{4}\right)$ solutions, and found significant reaction potential in $40 \mathrm{wt} \%-$ $80 \mathrm{wt} \% \mathrm{H}_{2} \mathrm{SO}_{4}$ range. Thus, heterogeneous processes may potentially be an effective degradation pathway.

In the current study, the uptake kinetics of the unsaturated alcohols, BO31, 4-penten-1-ol (PO41) and MBO331, into $20 \mathrm{wt} \%-80 \mathrm{wt} \% \mathrm{H}_{2} \mathrm{SO}_{4}$ were investigated, and reactive uptake coefficients $(\gamma)$ were determined. To the best of our knowledge, this study provides the first uptake kinetics measurements for these unsaturated alcohols into $\mathrm{H}_{2} \mathrm{SO}_{4}$ solution. The potential implications of our findings for the global atmosphere are also discussed.

\section{Experimental}

Uptake experiments were carried out using a rotated wettedwall reactor (RWW) coupled to a differentially pumped single-photon ionization time of flight mass spectrometer (SPI-TOFMS), which has been used in our previous studies $[13,14]$. The RWW consisted of a horizontal glass cylindrical flow reactor equipped with an external glass jacket for thermostat purposes, and a rotating inner cylinder (length $L=30 \mathrm{~cm}$ and inner radius $R=1.25 \mathrm{~cm}$ ) for supporting the liquid film. A small volume of $\mathrm{H}_{2} \mathrm{SO}_{4}$ (3-3.5 mL, corresponding to a film thickness of $\sim 0.1 \mathrm{~mm}$ ) was placed in the inner cylinder, which was rotated at $10-15 \mathrm{r} / \mathrm{min}$ to maintain a uniform film on the wall. A glass stirring bar rested on the bottom of the inner cylinder to ensure the solution was sufficiently mixed and could be easily spread. A helium/water vapor mixture in equilibrium with the acidic solution was used as the carrier gas, with a total flow rate of $212 \mathrm{STP} \mathrm{cm}^{-3} \mathrm{~min}^{-1}$ (STP conditions: $273 \mathrm{~K}, 1 \mathrm{~atm}$ (1 atm= $\left.1.013 \times 10^{5} \mathrm{~Pa}\right)$. This ensured constant solution acidity throughout experiments. Organic reactant compounds were introduced into the main flow of the reactor, by entraining their vapor into helium flow (21.2 STP $\mathrm{cm}^{-3} \mathrm{~min}^{-1}$ ), and allowing this flow through a movable injector centered in the rotating cylinder. The movable injector allowed for contact distance variations between the reactant gas and solution. Gas flows were monitored with calibrated electronic mass flow meters (SevenStar D08-1D/ZM, Beijing, China). All measurements were performed at a total pressure of $5-150$ Torr $\left(1\right.$ Torr $\left.=1.33 \times 10^{2} \mathrm{~Pa}\right)$ and temperature of $293 \mathrm{~K}$.

A differentially pumped SPI-TOFMS was employed to monitor reactant concentration variations in the gas-phase upon uptake. Mass spectra of the three unsaturated alcohols are shown in Figure 1, and all peaks were monitored in case of missing product ions. No ion peak belonging to a product was observed during the uptake measurements. Variation of ion peaks marked by * were used to calculate the uptake coefficients, because of their enhanced signal intensity (molecular ion peak for MBO331 and BO31, and fragment ion peak for PO41).

BO31 (99\%, Alfa Aesar), PO41 (98\%, Alfa Aesar), MBO331 (97\%, Alfa Aesar), and $\mathrm{H}_{2} \mathrm{SO}_{4}$ (>96 wt\%, Beijing Chemical Reagents Company) were used without further purification. $\mathrm{H}_{2} \mathrm{SO}_{4}$ solutions were prepared by mixing $\mathrm{H}_{2} \mathrm{SO}_{4}$ with $18 \mathrm{M} \Omega$-cm deionized water. $\mathrm{H}_{2} \mathrm{SO}_{4}$ solution composition was determined before and after each experiment by titration with a known concentration $\mathrm{NaOH}$ solution, and was found to vary by $<0.5 \mathrm{wt} \%$. The $\mathrm{H}_{2} \mathrm{SO}_{4}$ solution was replaced after each experiment.

\section{Results and discussion}

\subsection{Uptake measurements}

Uptake measurements were performed by exposing $\mathrm{H}_{2} \mathrm{SO}_{4}$ solutions to unsaturated alcohols, while monitoring the unsaturated alcohol signal intensity using VUV-SPI-TOFMS. Adsorption/desorption to/from solutions was evident from the signal decline and recovery. Figure 2 shows the temporal profiles of MBO331 signal during experiments with: (a) $20 \mathrm{wt} \%$, (b) $30 \mathrm{wt} \%$ and (c) $60 \mathrm{wt} \% \mathrm{H}_{2} \mathrm{SO}_{4}$ solutions. For these experiments, the injector was moved upstream, thus exposing the $\mathrm{H}_{2} \mathrm{SO}_{4}$ solutions to $\mathrm{MBO} 331$. For the $20 \mathrm{wt} \%$ $\mathrm{H}_{2} \mathrm{SO}_{4}$ solution, the transient signal decreased and then returned to its original level as the $\mathrm{H}_{2} \mathrm{SO}_{4}$ solution was saturated.

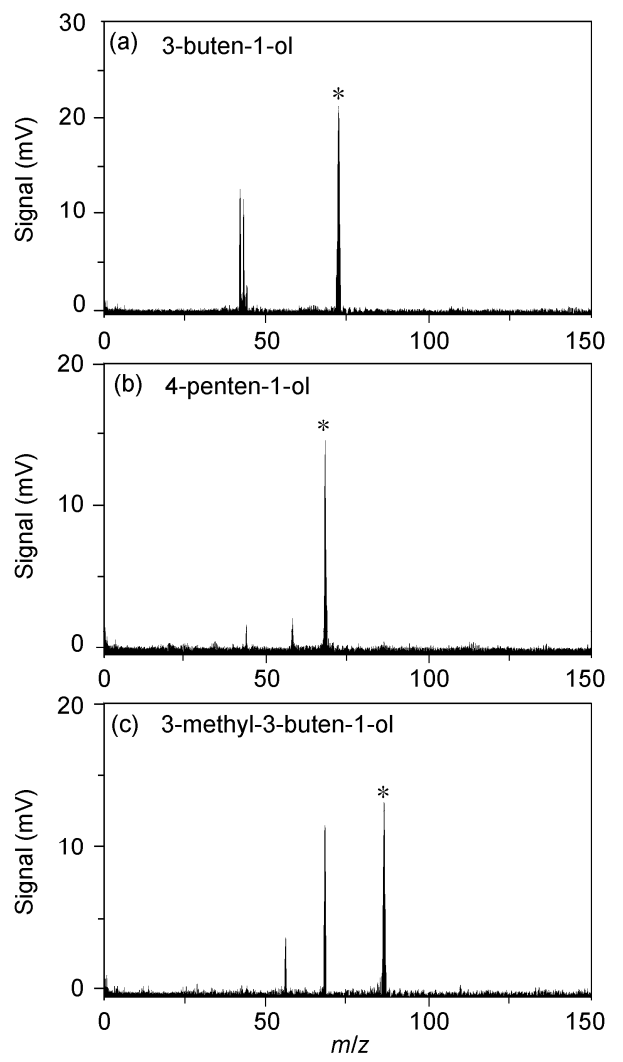

Figure 1 The SPI-TOFMS mass spectra of unsaturated alcohols. Ion peaks marked by * were used to calculate uptake coefficients. 

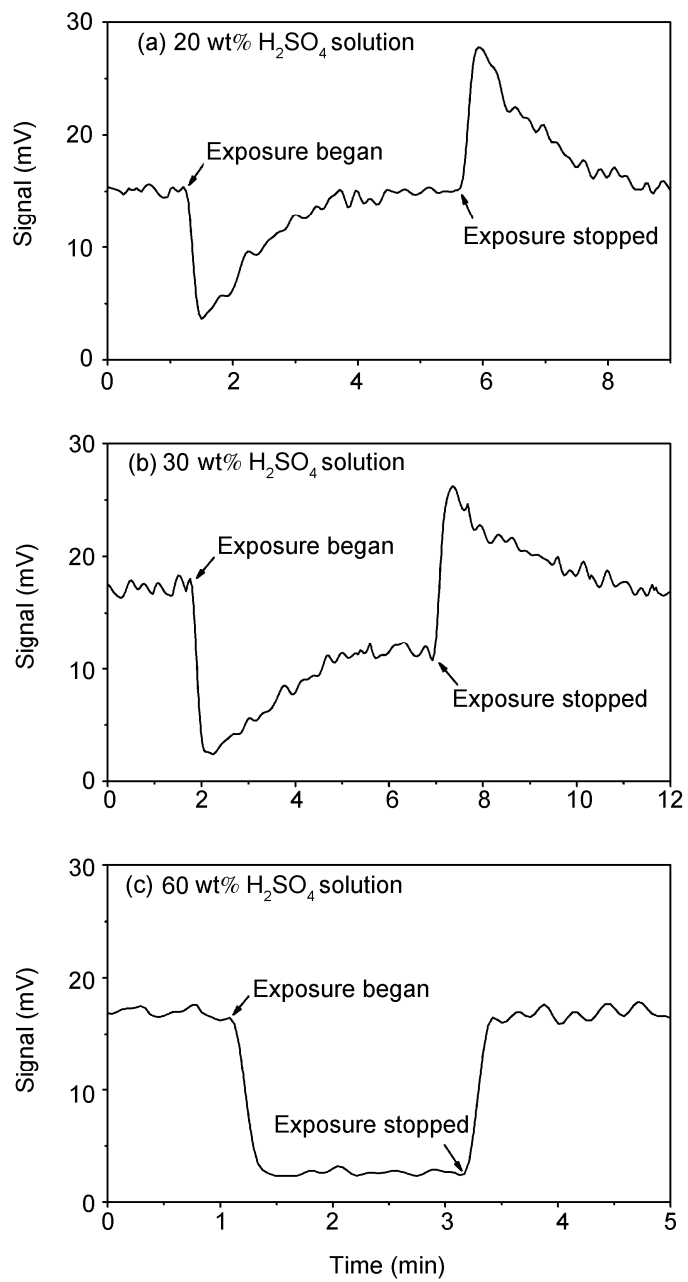

Figure 2 Typical time profiles of the MBO331 signal, showing uptake into (a) $20 \mathrm{wt} \%$, (b) $30 \mathrm{wt} \%$ and (c) $60 \mathrm{wt} \% \mathrm{H}_{2} \mathrm{SO}_{4}$ solutions. Observed uptake was (a) reversible, (b) reversible and reactive, and (c) reactive. $m / z=86$

Pushing the injector back to its initial position produced a secondary transient signal, corresponding to the release of MBO331 back to the gas phase. The similarity in shape and total area of the adsorption and desorption curves meant that MBO331 partitioned reversibly between the gas and solution phases. For the $60 \mathrm{wt} \% \mathrm{H}_{2} \mathrm{SO}_{4}$ solution, the uptake displayed a steady-state feature and exhibited no saturation over the experimental time scale, indicating that an irreversible reaction was dominant. In numerous experiments, two behavior types were observed for the variation in MBO331 signal (Figure 2(b)): MBO331 was adsorbed and then subsequently desorbed, but additionally a constant signal offset was observed at a long exposure time. This may have been because of the occurrence of an irreversible reaction.

The plots in Figure 2 suggested that multiple equilibrium/reaction mechanisms existed. At low acidity conditions (20 wt \%), dissolution equilibrium played a dominant role, and led to rapid saturation of the $\mathrm{H}_{2} \mathrm{SO}_{4}$ solution. When the $\mathrm{H}_{2} \mathrm{SO}_{4}$ solution was no longer exposed, the
MBO331 equilibrium shifted from the liquid to gas phases, corresponding to desorption. As acidity increased, dissolution equilibrium was not the only process occurring within the gas-liquid interaction. Some dissolved MBO331 may have irreversibly been converted to reaction product, resulting in a constant negative signal offset. When acidity increased further $(60 \mathrm{wt} \%)$, the irreversible reaction became predominant. Only irreversible reaction was apparent in Figure 2(c).

The other two unsaturated alcohols were less reactive to $\mathrm{H}_{2} \mathrm{SO}_{4}$ than MBO331. BO31 uptake was dominated by a reversible component for $20 \mathrm{wt} \%-50 \mathrm{wt} \% \mathrm{H}_{2} \mathrm{SO}_{4}$, and indicated no desorption for $80 \mathrm{wt} \% \mathrm{H}_{2} \mathrm{SO}_{4}$. Partially reactive uptake of PO41 was observed when solution acidity increased up to $50 \mathrm{wt} \%$, and reversible behavior was not observed for $70 \mathrm{wt} \%-80 \mathrm{wt} \% \mathrm{H}_{2} \mathrm{SO}_{4}$. This may have been because of discrepancies in molecular structure of the unsaturated alcohols, which are discussed in detail below.

\subsection{Calculation of reactive uptake coefficients}

To more accurately compare the reactivity of the three unsaturated alcohols, reactive uptake coefficients $(\gamma)$ were calculated. The calculation method was stated in detail elsewhere, and only a brief description is listed here [13,14]. When the experiment had just commenced, the movable injector was positioned at its maximum allowable downstream location. Once here, the acidic solution was unexposed to the reactant, and the unperturbed reactant gas concentration could be measured as the original signal, $S_{0}$. The injector was then moved upstream to expose the solution to reactant gas. Reactive uptake was indicated by a constant offset between the original and uptake signals $(S)$ with time. The first-order rate constant for reactant removal from the gas phase, $k_{\mathrm{obs}}\left(\mathrm{s}^{-1}\right)$, was calculated from:

$$
\ln \left(\frac{S}{S_{0}}\right)=k_{\mathrm{obs}} L / v_{\mathrm{ave}},
$$

where $L(\mathrm{~cm})$ is the contact distance of the gas and solution, and $v_{\text {ave }}\left(\mathrm{cm} \mathrm{s}^{-1}\right)$ is the average gas flow velocity. The surface rate constant for reactant gas removal, $k_{\text {gas-surface }}\left(\mathrm{s}^{-1}\right)$, can be determined by correcting $k_{\text {obs }}$ for diffusion according to the Fuller-Schettler-Gidding method [15-18]. Finally, $\gamma$ defined as the probability of loss per collision with the surface [19], could be calculated from:

$$
\gamma=\frac{4 k_{\text {gas-surface }} V}{\omega A},
$$

where $\omega\left(\mathrm{m} \mathrm{s}^{-1}\right)$ is the mean molecular speed of the reactant gas, $V\left(\mathrm{~cm}^{3}\right)$ is the volume of the reaction zone, and $A\left(\mathrm{~cm}^{2}\right)$ is the geometric area of the exposed solution.

Figure 3 describes the loss of MBO331 as a function of injector position. The variation in $\ln \left[S / S_{0}\right]$ was found to decrease linearly with contact distance. All decays followed 


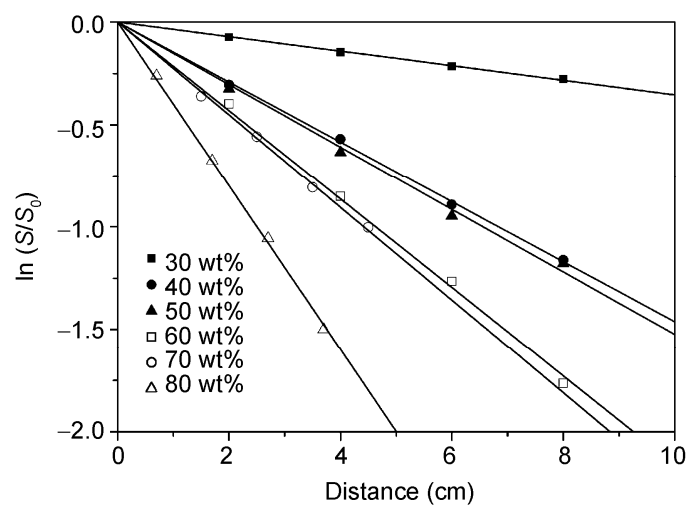

Figure 3 MBO331 signal as a function of injector distance, for $30 \mathrm{wt} \%$ $80 \mathrm{wt} \% \mathrm{H}_{2} \mathrm{SO}_{4}$ solutions.

pseudo-first order kinetics, and first-order decay rates $\left(k_{\mathrm{obs}}\right)$ were obtained from gradients using a linear regression method. After correcting for diffusion, uptake coefficients were determined using eq. (2), and are summarized in Table 1. This process was also carried out for BO31 and PO41.

From the data in Table 1, the reactive uptake coefficient for each unsaturated alcohol showed an increasing trend with acidity, implying that acidity dominated the uptake kinetics. The reactivity of the alcohols followed the trend: $\gamma$ (BO31) $<\gamma(\mathrm{PO} 41)<\gamma(\mathrm{MBO} 331)$. This could be explained by an electrophilic addition mechanism of $\mathrm{H}_{2} \mathrm{SO}_{4}$ to the $\mathrm{C}=\mathrm{C}$ double bond. The substituent pattern of carbon atoms in a $\mathrm{C}=\mathrm{C}$ double bond affects the bonds electron distribution. For MBO331 the methyl group connected to the $\mathrm{C}=\mathrm{C}$ double bond exerted a strong positive inducing effect, and rendered the double bond susceptible to electrophilic attack. Thus, MBO331 was more reactive to $\mathrm{H}_{2} \mathrm{SO}_{4}$ than the other unsaturated alcohols in this study. PO41 has a longer chain substituted group, which led to greater electron-donating ability than for BO31. In addition, the greater distance between the hydroxyl group and double bond in PO41 led to a lesser electron-withdrawing effect. Thus, the $\mathrm{C}=\mathrm{C}$ double bond of PO41 could be attacked more readily than that of
BO31.

The acidity of aerosols and cloud condensation nucleus $(\mathrm{CCN})$ has been reported to be in the range of $\mathrm{pH} 2-5$ [20,21]. However, significantly higher sulfate aerosol acidity, approaching values used in this study has also been reported [22,23] and used in other experiments [24-27]. Thus, this heterogeneous reaction could potentially occur in the ambient atmosphere. To elucidate the atmospheric significance of the uptake of BO31, PO41 and MBO331 into sulfuric acid aerosols, their loss rates at typical atmospheric conditions need to be determined. Experimental data from this study allows the individual estimation of atmospheric lifetimes for these three unsaturated alcohols, for their reaction with $\mathrm{H}_{2} \mathrm{SO}_{4}$. After consulting atmospheric conditions of $\mathrm{H}_{2} \mathrm{SO}_{4}$ content [22,23], $\gamma$ values were adopted from $60 \mathrm{wt} \%-80 \mathrm{wt} \% \mathrm{H}_{2} \mathrm{SO}_{4}$ data given in Table 1. The atmospheric lifetimes, $\tau$, of the unsaturated alcohols with regard to their uptake into $\mathrm{H}_{2} \mathrm{SO}_{4}$ solution could be estimated by: $\tau$ $=4 / \gamma \omega \sigma$, where $\omega$ is the mean molecular speed of the alcohol, and $\sigma$ is the area density of the atmospheric sulfate aerosol $\left(\sim 2 \times 10^{-7} \mathrm{~cm}^{2} / \mathrm{cm}^{3}\right.$ [28]). This calculation provided atmospheric lifetimes of 74.9-1.1 d for BO31, $17.4 \mathrm{~d}$ to10.1 $\mathrm{h}$ for PO41 and $4.0 \mathrm{~d}$ to $8.0 \mathrm{~h}$ for MBO331. Compared to homogeneous reactions with $\mathrm{OH} / \mathrm{O}_{3} / \mathrm{NO}_{3}$, which lead to atmosphere lifetimes of a few hours $[8,10]$, the heterogeneous reaction is expected to be less important. However, irreversible reactions resulted in atmospheric lifetimes of a few hours for PO41 and MBO331, when the solution acidity increased to $80 \mathrm{wt} \%$. Such lifetimes are very close to the homogeneous reaction values mention above. Thus, the heterogeneous reaction with sulfuric acid aerosols may be a significant degradation pathway for unsaturated alcohols. This is particularly so for freshly nucleated aerosols potentially formed prior to any neutralization.

\section{Conclusions}

Unsaturated alcohols are important components in complex

Table 1 Reactive uptake coefficients with varying wt $\% \mathrm{H}_{2} \mathrm{SO}_{4}$ solutions

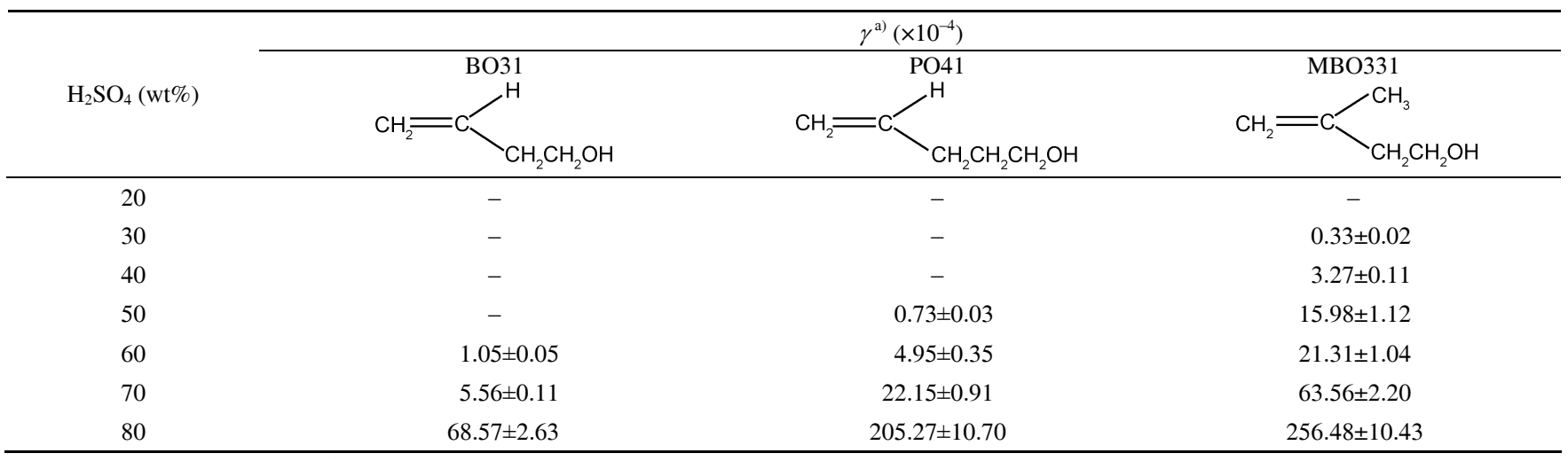

a) Each value is the average of at least three measurements, and the error corresponds to one standard deviation $(\sigma)$. 
mixtures of OVOCs, which are emitted from biogenic and anthropogenic sources, and are relevant in atmospheric chemistry. The present study addressed the uptake kinetics of $\mathrm{BO} 31, \mathrm{PO} 41$ and $\mathrm{MBO} 331$ into $\mathrm{H}_{2} \mathrm{SO}_{4}$ solutions with composition ranges of $20 \mathrm{wt} \%-80 \mathrm{wt} \%$. Reactive uptake coefficients were acquired and reported for the first time $(60$ wt $\%-80 \mathrm{wt} \%, 50 \mathrm{wt} \%-80 \mathrm{wt} \%$ and $30 \mathrm{wt} \%-80 \mathrm{wt} \%$ for $\mathrm{BO} 31, \mathrm{PO} 41$ and $\mathrm{MBO} 331$, respectively), indicating that $\mathrm{H}_{2} \mathrm{SO}_{4}$ acidity controlled the reactive uptake kinetics. Reactivity followed the trend $\mathrm{BO} 31<\mathrm{PO} 41<\mathrm{MBO} 331$, which may have been because of the electrophilic addition mechanism of $\mathrm{H}_{2} \mathrm{SO}_{4}$ to the $\mathrm{C}=\mathrm{C}$ double bond. Atmospheric lifetimes of the three unsaturated alcohols were estimated. These suggested that heterogeneous reaction with sulfuric acid aerosols may be a potential degradation pathway, and should not be neglected.

This work was supported by the Knowledge Innovation Program of Chinese Academy of Sciences (KJCX2-YW-N24, KZCX2-YW-205) and the National Natural Science Foundation of China (40925016, 40830101).

1 Jang M, Kamens R M. Atmospheric secondary aerosol formation by heterogeneous reactions of aldehydes in the presence of a sulfuric acid aerosol catalyst. Environ Sci Technol, 2001, 35: 4758-4766

2 Jang M, Czoschke N M, Lee S, et al. Heterogeneous atmospheric aerosol production by acid-catalyzed particle-phase reactions. Science, 2002, 298: 814-817

3 Jang M, Lee S, Kamens R M. Organic aerosol growth by acidcatalyzed heterogeneous reactions of octanal in a flow reactor. Atmos Environ, 2003, 37: 2125-2138

4 Liggio J, Li S M, Mclaren R. Heterogeneous reactions of glyoxal on particulate matter: Identification of acetals and sulfate esters. Environ Sci Technol, 2005, 39: 1532-1541

5 Goldan P D, Kuster W C, Fehsenfeld F C, et al. The observation of a C5 alcohol emission in a North American pine forest. Geophys Res Lett, 1993, 20: 1039-1042

6 König G, Brunda M, Puxbaum H, et al. Relative contribution of oxygenated hydrocarbons to the total biogenic VOC emissions of selected mid-European agricultural and natural plant species. Atmos Environ, 1995, 29: 861-874

7 Fall R, Karl T, Jordan A, et al. Biogenic C5 VOCs: Release from leaves after freeze-traw wounding and occurrence in air at a high mountain observatory. Atmos Environ, 2001, 35: 3905-3916

8 Cometto P M, Dalmasso P R, Taccone R A, et al. Rate coefficients for the reaction of $\mathrm{OH}$ with a series of unsaturated alcohols between 263 and $371 \mathrm{~K}$. J Phys Chem A, 2008, 112: 4444-4450

9 Carrasco N, Doussin J F, O'Connor M, et al. Simulation chamber studies of the atmospheric oxidation of 2-methyl-3-buten-2-ol: Reaction with hydroxyl radical and ozone under a variety of conditions.
J Atmos Chem, 2007, 56: 33-55

10 Noda J, Nyman G, Langer S. Kinetics of the gas-phase reaction of some unsaturated alcohols with the nitrate radical. J Phys Chem A, 2002, 106: 945-951

11 Wang L, Ge M F, Wang W G. Kinetic study of the reaction of chlorine atoms with 3-methyl-3-buten-1-ol. Chinese Sci Bull, 2009, 54: 3808-3812

12 Nozière B, Voisin D, Longfellow C A, et al. The uptake of methyl vinyl ketone, methacrolein, and 2-methyl-3-butene-2-ol onto sulfuric acid solutions. J Phys Chem A, 2006, 110: 2387-2395

13 Liu Z, Ge M F, Yin S, et al. Uptake and reaction kinetics of $\alpha$-pinene or $\beta$-pinene with sulfuric acid solutions. Chem Phys Lett, 2010, 491: $146-150$

14 Yin S, Ge M F, Wang W G, et al. Uptake of gas-phase alkylamines by sulfuric acid. Chinese Sci Bull, 2011, 56: 1241-1245

15 Murphy D M, Fahey D W. Mathematical treatment of the wall loss of a trace species in denuder and catalytic converter tubes. Anal Chem, 1987, 59: 2753-2759

16 Hanson D R, Burkholder J B, Howard C J, et al. Measurement of hydroxyl and hydroperoxy radical uptake coefficients on water and sulfuric acid surfaces. J Phys Chem, 1992, 96: 4979-4985

17 Gershenzon Y M, Grigorieva V M, Ivanov A V, et al. $\mathrm{O}_{3}$ and $\mathrm{OH}$ sensitivity to heterogeneous sinks of $\mathrm{HO}_{\mathrm{x}}$ and $\mathrm{CH}_{3} \mathrm{O}_{2}$ on aerosol particles. Faraday Discuss, 1995, 100: 83-100

18 Fuller E N, Schettler P D, Giddings J C. A new method for prediction of binary gas-phase diffusion coefficients. Ind Eng Chem, 1966, 58: $19-27$

19 Howard C J. Kinetic measurements using flow tubes. J Phys Chem, 1979, 83: 3-9

20 Ganor E. A method for identifying sulfuric acid in single cloud and for droplets. Atmos Environ, 1999, 33: 4235-4242

21 Hindman E E, Borys R D, Lowenthal D H, et al. Long-term, wintertime aerosol, cloud and precipitation measurements in the Northern Colorado Rocky Mountains, USA. Atmos Res, 2006, 82: 194-202

22 Ferek R J, Lazrus A L, Haagenson P L, et al. Strong and weak acidity of aerosols collected over the Northeastern United States. Environ Sci Technol, 1983, 17: 315-324

23 Curtius J, Sierau B, Arnold F, et al. Measurement of aerosol sulfuric acid. 2. Pronounced layering in the free troposphere during the second Aerosol Characterization Experiment (ACE 2). J Geophys Res Atmos, 2001, 106: 31975-31990

24 Esteve W, Nozière B. Uptake and reaction kinetics of acetone, 2-butanone, 2,4-pentanedione, and acetaldehyde in sulfuric acid solutions. J Phys Chem A, 2005, 109: 10920-10928

25 Timonen R S, Leu M T. Interaction of ethyl alcohol vapor with sulfuric acid solutions. J Phys Chem A, 2006, 110: 6660-6666

26 Levitt N P, Zhao J, Zhang R. Heterogeneous chemistry of butanol and decanol with sulfuric acid: Implications for secondary organic aerosol formation. J Phys Chem A, 2006, 110: 13215-13220

27 Wang L, Lal V, Khalizov A F, et al. Heterogeneous chemistry of alkylamines with sulfuric acid: Implications for atmospheric formation of alkylaminium sulfate. Environ Sci Technol, 2010, 44: 2461-2465

28 Godin S, Poole L R. Scientific Assessment of Ozone Depletion. Global Ozone Research and Monitoring Project-Report No. 44. Geneva: World Meteorological Organization, 1998

Open Access This article is distributed under the terms of the Creative Commons Attribution License which permits any use, distribution, and reproduction in any medium, provided the original author(s) and source are credited. 